\title{
Expression of the Epstein-Barr virus in lymphoproliferative diseases of the lung
}

\author{
MISUZU SHIMAKAGE ${ }^{1,6}$, HARUHIKO SAKAMOTO ${ }^{2}$, SHIZUKO HARADA ${ }^{3}$, \\ TOSHIYUKI SASAGAWA ${ }^{4}$ and KEN KODAMA ${ }^{5}$ \\ ${ }^{1}$ Clinical Reseach Institute, National Hospital Organization, Osaka National Hospital, 2-1-14 Hoenzaka, Chuo-ku, \\ Osaka 540-0006; ${ }^{2}$ Department of Pathology, Faculty of Medicine, Kagawa University, 1750-1, Ikenobe, \\ Miki-cho, Kita-gun, Kagawa Prefecture 761-0701; ${ }^{3}$ Department of Virology I, National Institute of \\ Infectious Diseases, 1-23-1 Toyama, Shinjuku-ku, Tokyo 162-8640; ${ }^{4}$ School of Health Sciences, \\ Faculty of Medicine, Kanazawa University, 5-11-80, Kodatsuno 920-6942; ${ }^{5}$ Department of \\ Thoracic Surgery, Osaka Medical Center for Cancer and Cardiovascular Diseases, \\ 3-Nakamichi, 1-chome, Higashinari-ku, Osaka 537-8511, Japan
}

Received January 18, 2007; Accepted March 2, 2007

\begin{abstract}
There have been few studies regarding the etiology of lymphoproliferative disorders of the lung. To examine the possible involvement of the Epstein-Barr virus (EBV) in these diseases, EBV mRNAs, proteins and DNA, were detected. Two non-Hodgkin's lymphomas (NHL) originating in the lung, 5 mucosal-associated lymphoid tissue lymphomas (MALT lymphoma) of the lung, 1 lymphoid hyperplasia of the lung and 1 lymphoid interstitial pneumonia (LIP), were subjected to mRNA in situ hybridization, indirect immunofluorescence staining and PCR. mRNA in situ hybridization using BamHIW, BamHIY1Y2, the Epstein-Barr virus nuclear antigen (EBNA) and the EBV encoded small non-polyadenylated RNA (EBER1) probe revealed signals in all the examined samples, although some samples showed weak signals by using the EBER 1 probe. Indirect immunofluorescence staining using the anti-leader protein, anti-EBNA2, the anti-latent member protein-1 and anti-Bam HIZ coding
\end{abstract}

Correspondence to: Dr Misuzu Shimakage, Present address: ${ }^{6}$ Department of Pediatrics, National Hospital Organization, Wakayama National Hospital, 1138 Wada, Mihama-Town, Hidakagun, Wakayama Prefecture 644-0044, Japan

E-mail: misuzu_s@wakayama2.hosp.go.jp

Abbreviations: EBV, Epstein-Barr virus; PCR, polymerase chain reaction; EBNA LP, Epstein-Barr virus nuclear antigen-leader protein; EBNA2, Epstein-Barr virus nuclear antigen-2; LMP1. latent membrane protein-1; EBER1, EBV encoded small non-polyadenylated RNAs; BZLF1, BamHIZ coding leftward reading frame-1; NHL, non-Hodgkin's lymphoma; MALT lymphoma, mucosal-associated lymphoid tissue lymphoma; LIP, lymphoid interstitial pneumonia

Key words: in situ hybridization, lung lymphoma, mucosalassociated lymphoid tissue lymphoma, lymphoid interstitial pneumonia leftward reading frame-1 antibodies showed definitive fluorescence. PCR also revealed EBV DNA in these specimens. EBV infected all the lymphoproliferative diseases of the lung irrespective of the histological or clinical stages. Furthermore, EBV infected not only the atypical lymphocytes but also the macrophages in the tissues of these diseases. These results suggest that the expression of EBV could be involved in the pathogenesis of many lymphoproliferative diseases of the lung.

\section{Introduction}

Lymphoproliferative disorders of the lung contain a wide spectrum of diseases, from lymphoid interstitial pneumonia (LIP) to malignant lymphoma such as non-Hodgkin's lymphoma (NHL). Among the patients with LIP or lymphoid hyperplasia of the lung, there are some who suffer from a recurrence of these diseases and many years later, develop NHL. Approximately 5\% of the LIP cases transform to lymphoma (1). Although the mechanism that triggers this progression remains unclear, we suspect that recurrent or long-term infection could be correlated with progression.

The Epstein-Barr virus (EBV) is a ubiquitous virus that infects both adults and adolescents throughout the world. It is a well-established causative agent of infectious mononucleosis, and is associated with endemic Burkitt's lymphoma, nasopharyngeal carcinoma, Hodgkin's disease, and diffuse large B-cell lymphoma in immunosuppressed hosts (2). We have shown that EBV is related to many other human cancers as well (3-12). In thyroid carcinoma, EBV correlates with the tumor progression of papillary to undifferentiated carcinoma (11). The transforming genes of EBV are suspected to be in the regions of the EBV-determined nuclear antigen-2 (EBNA2) $(13,14)$, and the latent membrane protein-1 (LMP1) (15). EBNA-coding sequences commonly share the BamHIW region which is repeated $\sim 10$-fold in an EBV genome, and the BamHIY1Y2 region. EBV encoded small non-polyadenylated RNAs (EBER1) are abundantly present 
in latently EBV-infected cells (16). The BamHIZ coding leftward reading frame-1 (BZLF1) protein initiates the switch from latent to lytic infection (17).

In order to examine the relationship between EBV and lymphoproliferative diseases of the lung, we performed mRNA in situ hybridization using 4 different EBV probes and indirect immunofluorescence staining using 4 different monoclonal antibodies against EBV. The BamHIW and EBNA2 probes, and anti-EBNA2 and anti-LMP1 antibodies were selected to detect the transformation by EBV. Furthermore, the BamHIY1Y2 probe and the anti-leader protein (LP) antibody could also be associated with EBV transformation (18).

EBV expression was detected in all the lymphoproliferative diseases of the lung. The EBV DNA was also confirmed by PCR. The results presented herein indicate that the mRNAs and proteins of EBV are expressed in lymphoproliferative diseases of the lung, suggesting that EBV could be a causative agent of these disorders.

\section{Materials and methods}

Patients. Formalin-fixed paraffin-embedded tissue samples from 2 patients with NHL, 5 patients with mucosal-associated lymphoid tissue lymphoma (MALT lymphoma), 1 patient with lymphoid hyperplasia and 1 patient with LIP, were selected from the 1994 to 2002 files at Osaka Medical Center for Cancer and Cardiovascular Diseases. All were B-cell type lymphoproliferations of the lung. For the negative controls, 8 samples of normal edge of lung cancers were examined. All were Japanese. None of them had features indicative of an immunocompromised state. Informed consent was obtained from each patient.

Probes. BamHIW probes were transcribed from $2.27 \mathrm{~kb}$ EBV BamHIW fragments from which the 'Alu-family'-like sequence had been deleted. The BamHIW fragment of EBV is a highly repetitive sequence that contains the mRNA leader sequence for EBNAs (19). The fragment was cloned into the pBluescript II SK ${ }^{+}$vector. The cDNA of the BamHIY1Y2 region was also cloned into pBluescript $\mathrm{II} \mathrm{SK}^{+}$, and the size of this cDNA was $153 \mathrm{bp}$. The antisense and sense probes were labeled with digoxigenin-11-UTP by in vitro transcription with $\mathrm{T} 3$ and $\mathrm{T} 7$ polymerases, respectively, using a commercial kit (Boehringer Mannheim, Mannheim, Germany). EBNA2 cDNA (14802-48583 including a spliced sequence) and EBER1 cDNA (6629-6795) were synthesized with RT-PCR by the method reported by Tierney et al (20), and cloned into the pGEM-T Easy Vector (Promega, Madison, WI, USA). The sizes of these cDNAs were 386 and $167 \mathrm{bps}$, respectively. The antisense and sense RNA probes were labeled with digoxigenin-11-UTP by in vitro transcription with SP6 and T7 polymerases using a commercial kit (Boehringer Mannheim). The labeled BamHIW and EBNA2 riboprobes were then fragmented to about 100 bases in length by alkaline hydrolysis. The sense probe served as the negative control.

Messenger RNA in situ hybridization. Paraffin sections were prepared from formalin-fixed tissues from biopsied or surgically resected materials. Serial sections, of 3-5 $\mu \mathrm{m}$, were cut. After dewaxing and dehydration with graded ethanol, the slides were treated with $0.2 \mathrm{~N} \mathrm{HCl}$ for $15 \mathrm{~min}$ at room temperature (RT) and rinsed with phosphate-buffered saline (PBS) for $5 \mathrm{~min}$ at RT. Then they were treated with $50 \mu \mathrm{g} / \mathrm{ml}$ proteinase $\mathrm{K}$ in $\mathrm{PBS}$ for $15 \mathrm{~min}$ at $37^{\circ} \mathrm{C}$, and immersed in $2 \mathrm{mg}$ / $\mathrm{ml}$ glycine in PBS for $10 \mathrm{~min}$ at RT. They were then refixed with $4 \%$ paraformaldehyde in PBS for $15 \mathrm{~min}$ at RT and washed twice with PBS for $3 \mathrm{~min}$ at RT. Then they were treated with $0.1 \mathrm{M}$ triethanolamine $(\mathrm{pH} 8.0)$ for $10 \mathrm{~min}$ at RT. After washing with PBS, the sections were dehydrated with ethanol and hybridized for $40 \mathrm{~h}$ at $37^{\circ} \mathrm{C}$ for EBNA2 and EBER $1,39^{\circ} \mathrm{C}$ for EBNA LP and at $45^{\circ} \mathrm{C}$ for BamHIW in $4 \mathrm{X}$ SSC, $50 \%$ formamide, 1X Denhardt's solution, $5 \%$ dextran sulfate, $0.5 \mathrm{mg} / \mathrm{ml}$ salmon sperm DNA, $0.5 \mathrm{mg} / \mathrm{ml}$ yeast tRNA and $10 \mathrm{mM}$ dithiothreitol. After hybridization, the sections were washed twice with 2X SSC for $30 \mathrm{~min}$ and then twice with $0.5 \mathrm{X} \mathrm{SSC}$ for $20 \mathrm{~min}$ with gentle shaking at RT. They were then blocked with $1 \%$ skim milk (Difco) in $100 \mathrm{mM}$ Tris, $0.15 \mathrm{M} \mathrm{NaCl}(\mathrm{pH} 7.5)$ for $30 \mathrm{~min}$ at RT. Next, they were reacted with 1:100 diluted (for EBNA2) and 1:200 diluted (for BamHIW, BamHIY1Y2 and EBER1) alkaline phosphatase-labeled anti-DIG antibody (Boehringer Mannheim) in blocking buffer for $2 \mathrm{~h}$ at RT. After washing, the sections were incubated with Nitroblue tetrazolium and $\mathrm{X}$ phosphate (Boehringer Mannheim) in buffer containing 0.1 M Tris, $0.1 \mathrm{M} \mathrm{NaC1}, 0.005 \mathrm{M} \mathrm{MgCl}_{2}$ and $1 \mathrm{mM}$ levamisole ( $\mathrm{pH}$ 9.6) for $16 \mathrm{~h}$ at RT. Visualization was stopped with EDTA, and then the slides were dehydrated with graded ethanol and xylene, and sealed with malinol. These methods are a modified version of those previously reported $(3-12,18)$.

Double staining for macrophage marker and BamHIW $m R N A$ in situ hybridization. The slides were examined BamHIW in situ hybridization using the same method as described above. Subsequently, they were reacted with the antibody, CD68, purchased from Dako (Glostrup, Denmark), and stained with diaminobenzidine according to the manufacturer's instructions.

Indirect immunofluorescence staining. The formalin-fixed paraffin-embedded tissue samples and control specimens were cut into serial sections of 3-5 $\mu \mathrm{m}$. After dewaxing and dehydration, the sections were autoclaved in $10 \mathrm{mM}$ citrate buffer (pH 6.0) for $10 \mathrm{~min}$ at $120^{\circ} \mathrm{C}$ to detect EBNA2, EBNA LP and BZLF1. Alternatively, the samples were digested for $15 \mathrm{~min}$ with proteinase $\mathrm{K}$ at a concentration of $1 \mathrm{mg} / \mathrm{ml}$ in $50 \mathrm{mM}$ Tris- $\mathrm{HCl}(\mathrm{pH} 7.6)$ at RT to detect LMP1. The sections were then blocked with 10-times-diluted EBV-negative human serum and $20 \%$ normal goat serum for $30 \mathrm{~min}$ at RT. The monoclonal anti-EBNA2 antibody, PE2, the anti-LMP1 antibody, CS1-4, the anti-BZLF1 antibody (Dako) and the anti-EBNA LP antibody, JF186 (21), were diluted 10x with PBS and reacted for $90 \mathrm{~min}$ at $37^{\circ} \mathrm{C}$. After washing with PBS, biotinylated goat anti-mouse $\lg \mathrm{G}$ (Vector, Burlingame, CA, USA ) was diluted $75 \mathrm{x}$ with PBS and reacted for $60 \mathrm{~min}$ at $37^{\circ} \mathrm{C}$. After washing, streptavidin-fluorescein isothiocyanate conjugate (Bethesda Research Laboratory, Gaithersburg, MD, USA) diluted 200x was reacted for $45 \mathrm{~min}$ at RT. After washing, the slides were sealed with Perma Fluor (Japan Tanner, Kobe, Japan). The negative controls of the tissue samples were reacted with 10 -times-diluted normal mouse 
Table I. Summary of the results.

\begin{tabular}{|c|c|c|c|c|c|c|c|c|c|c|c|c|}
\hline \multirow[b]{2}{*}{ Case } & \multirow[b]{2}{*}{ Age } & \multirow[b]{2}{*}{ Sex } & \multirow[b]{2}{*}{ Histology } & \multicolumn{4}{|c|}{ ISH } & \multicolumn{4}{|c|}{ IF } & \multirow[b]{2}{*}{ PCR } \\
\hline & & & & BamHIW & Y1Y2 & EBNA & EBER1 & EBNA2 & LP & BZLF1 & LMP1 & \\
\hline 1 & 53 & $\mathrm{M}$ & NHL & ++ & + & ++ & ++ & $\mathrm{w}+$ & +- & + & w+ & + \\
\hline 2 & 51 & $\mathrm{~F}$ & NHL & + & + & + & $\mathrm{w}+$ & + & + & + & ++ & + \\
\hline 3 & 54 & $\mathrm{M}$ & MALToma & ++ & $\mathrm{w}+$ & $\mathrm{w}+$ & $\mathrm{w}+$ & + & w+ & + & +- & + \\
\hline 4 & 61 & M & MALToma & ++ & ++ & ++ & + & $\mathrm{w}+$ & - & $\mathrm{w}+$ & - & NT \\
\hline 5 & 66 & $\mathrm{~F}$ & MALToma & + & + & + & w+ & + & + & + & $\mathrm{w}+$ & NT \\
\hline 6 & 50 & M & MALToma & ++ & ++ & ++ & $\mathrm{w}+$ & $\mathrm{w}+$ & + & $\mathrm{w}+$ & $\mathrm{w}+$ & NT \\
\hline 7 & 62 & $\mathrm{~F}$ & MALToma & + & + & + & $\mathrm{w}+$ & + & + & + & $\mathrm{w}+$ & + \\
\hline 8 & 51 & $\mathrm{M}$ & Lym.hyperpl. & + & ++ & ++ & + & w+ & - & - & + & NT \\
\hline 9 & 37 & $\mathrm{M}$ & LIP & ++ & + & + & $\mathrm{w}+$ & + & w+ & $\mathrm{w}+$ & + & NT \\
\hline
\end{tabular}

NHL, non-Hodgkin's lymphoma, diffuse large B-cell type; MALToma, mucosal-associated lymphoid tissue lymphoma; Lym.hyperpl., lymphoid hyperplasia; LIP, lymphoid interstitial pneumonia; ++, strongly positive; w+, weakly positive; +-, equivocal; NT, not tested.

IgG. These methods are identical to those we have used to study other human cancers $(3-12,18)$.

Nested PCR. DNA was extracted from the frozen tissues. The primers used for the 1 st round of PCR were: 5'CCAGA CAGCAGCCAATTCTC3' (nucleotide positions of BamHIW 1087-1106), and 5'CCTAAGAAGGCACCGGTC3' (15031520). The primers used for the 2nd round of PCR were: 5'GTAAGAGGGGGTCTTCTAC3' (1196-1214), and 5'CCA GAGGTAAGTGGACTT3' (1399-1416). The resulting 2nd round product was $220 \mathrm{bp}$. The PCRs were carried out in a thermal cycler Gene Amp 9600-R (Perkin Elmer). The reaction mixture contained $100 \mathrm{ng}$ to $1 \mu \mathrm{g}$ template DNA or $10 \mathrm{ng}$ positive control DNA (Namalwa and Raji), $0.1 \mathrm{nmol}$ of each primer, and $200 \mu \mathrm{M}$ each of dATP, dGTP, dCTP and dTTP in $1 \mathrm{X}$ amplification buffer (10 mM Tris- $\mathrm{HCl}, \mathrm{pH} 8.3$; $50 \mathrm{mM} \mathrm{KCl} ; 1.5 \mathrm{mM} \mathrm{MgCl} ; 0.01 \% \mathrm{~W} / \mathrm{V}$ gelatin) and $2.5 \mathrm{U}$ Taq or LA Taq polymerase (Perkin Elmer/TaKaRa) in a total volume of $100 \mu \mathrm{l}$. The samples were treated for $5 \mathrm{~min}$ at $94^{\circ} \mathrm{C}$ and amplified by 40 cycles of PCR, each consisting of $1 \mathrm{~min}$ of denaturing at $94^{\circ} \mathrm{C}, 30 \mathrm{sec}$ of annealing at $55^{\circ} \mathrm{C}$, and $1 \mathrm{~min}$ of extension at $72^{\circ} \mathrm{C}$. After treating for $10 \mathrm{~min}$ at $72^{\circ} \mathrm{C}$, the DNA was concentrated by ethanol precipitation, electrophoresed on a $1.8 \%$ agarose gel in TAE buffer ( $40 \mathrm{mM}$ Tris$\mathrm{HCl}, \mathrm{pH} 8.0,5 \mathrm{mM}$ sodium acetate, $1 \mathrm{mM}$ EDTA) and stained with $0.5 \mu \mathrm{g} / \mathrm{ml}$ ethidium bromide. This method has already been described (3).

\section{Results}

The results are summarized in Table I. In BamHIW mRNA in situ hybridization, signals were detected in the cytoplasm in all the sections hybridized with the antisense probe (Fig. 1B) but not with the sense probe (Fig. 1C). This result indicates that EBV infected all the lymphoproliferative disorders of the lung irrespective of the histological or clinical diagnosis. In EBNA LP (BamHIY1Y2) mRNA in situ hybridization, signals were detected in the cytoplasm in all the sections hybridized with the antisense probe (Fig. 1D) but not with the sense probe (Fig. 1E). Signals were weak in case 3. In EBNA2 mRNA in situ hybridization, signals were also detected in the cytoplasm in all cases hybridized with the antisense probe (Fig. 1F) but not with the sense probe (Fig. 1G), and signals were weak in case 3. In EBER1 RNA in situ hybridization, signals were detected in the nuclei in all cases hybridized with the antisense probe (Fig. 1H) but not with the sense probe, and the signals were weak in cases 2, 3, 5, 6 and 9. The normal part of well-differentiated adenocarcinoma of the lung showed few signals with the antisense probe of EBER1 (Fig. 1I).

We further examined the EBV protein expression by indirect immunofluorescence staining, due to higher sensitivity than immunohistochemistry. Immunofluorescence staining using the anti-EBNA2 antibody was prominent in the nuclei of lymphoma cells (Fig. 2A) or atypical lymphocytes, although fluorescence was weak in cases 1, 4, 6 and 8. Immunofluorescence staining using the anti-BZLF1 antibody revealed fluorescence in the nuclei of lymphoma cells (Fig. 2B) or atypical lymphocytes. Cases 4, 6 and 9 showed weak fluorescence. Immunofluorescence staining using the antiLMP1 antibody revealed fluorescence in the membranes of lymphoma cells (Fig. 2C) or atypical lymphocytes. Cases 1, 5, 6 and 7 showed weak fluorescence and case 4 showed no fluorescence. Immunofluorescence staining using the antiEBNA LP antibody was prominent in the nuclei of lymphoma cells (Fig. 2D) or atypical lymphocytes, although fluorescence was weak in cases 3 and 9, and cases 4 and 8 showed no fluorescence.

EBV DNA was detected by PCR. DNA was extracted from the resected cancer tissues (T) and the normal cut end (N) of each of the 4 of the 9 cases. The content of DNA was confirmed with primers of the housekeeping gene, cyclin A (Fig. 3A). EBV DNA was amplified in the region of BamHIW in case 7 , but not in cases $1 \mathrm{~N}, 2 \mathrm{~T}$, and $3 \mathrm{~T}$ (Fig. 3B). Reexamination of PCR with the enzyme LA Taq amplified EBV DNA in the cases of 2T and 3T. Case $1 \mathrm{~N}$ could not be amplified in this experiment and as it possibly contained little lymphocytic infiltration (Fig. 3C). 




Figure 1. mRNA in situ hybridizations of lymphoproliferative diseases of the lung. (A) H\&E staining of case 5. (B) mRNA in situ hybridization with the BamHIW antisense probe of case 5. (C) mRNA in situ hybridization with the BamHIW sense probe of case 5. (D) mRNA in situ hybridization with the EBNA LP antisense probe of case 4. (E) mRNA in situ hybridization with the EBNA LP sense probe of case 4. (F) mRNA in situ hybridization with the EBNA2 antisense probe of case 1. (G) mRNA in situ hybridization with the EBNA2 sense probe of case 1. (H) mRNA in situ hybridization with the EBER1 antisense probe of case 7. (I) mRNA in situ hybridization with the EBER1 antisense probe of the normal part of well differentiated lung adenocarcinoma (negative control). x200. A, B and C, D and E, F and G are the same field of sequential sections, respectively.
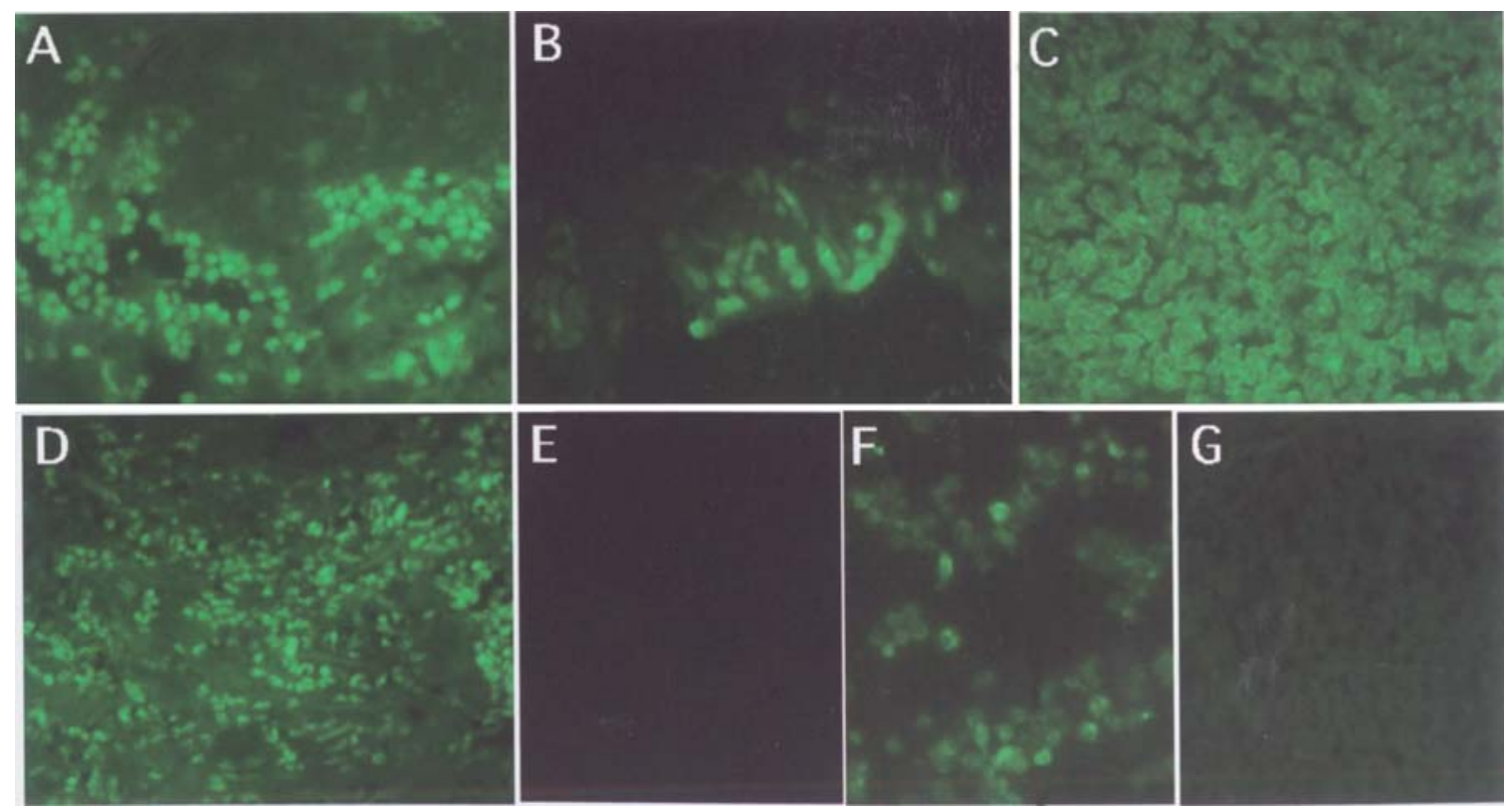

Figure 2. Indirect immunofluorescence staining of lymphoproliferative diseases of the lung. (A) Immunofluorescence with the monoclonal antibody against EBNA2 of case 1. (B) Immunofluorescence with the monoclonal antibody against BZLF1 of case 5. (C) Immunofluorescence with the monoclonal antibody against LMP1 of case 1. (D) Immunofluorescence with the monoclonal antibody against EBNA LP of case 6. (E) Immunofluorescence with the monoclonal antibody against EBNA LP of the EBV-negative B-cell line, BJAB (negative control for EBNA LP). (F) Immunofluorescence with the monoclonal antibody against EBNA LP of the EBV-positive B-cell line, B95-8 (positive control for EBNA LP). (G) Immunofluorescence with the normal mouse IgG of case 6 (negative control). x200. 


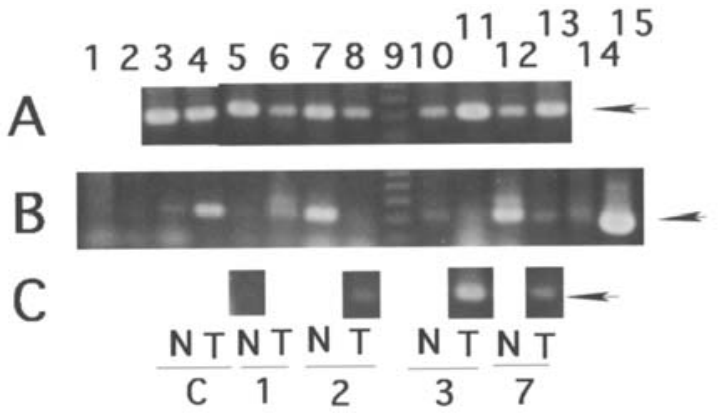

Figure 3. Results of PCR. Lane 1, no DNA; Lane 2, DNA extracted from the tonsils of an EBV-negative child; Lane 3, normal tissue of the reference case (lung cancer); Lane 4, cancerous tissue of the reference case (lung cancer); Lane 5, normal tissue of case 1; Lane 6, tumor tissue of case 1; Lane 7, normal tissue of case 2; Lane 8, tumor tissue of case 2; Lane 9, molecular weight markers; Lane 10, normal tissue of case 3; Lane 11, tumor tissue of case 3; Lane 12, normal tissue of case 7; Lane 13, tumor tissue of case 7; Lane 14, positive control DNA of the EBV-positive cell line, Namalwa; Lane 15, positive control DNA of the EBV-positive cell line, B95-8. (A) Amplification with the primer of cyclin A for the detection of extracted DNA with the enzyme Taq polymease (TaKaRa, Kyoto, Japan). (B) Amplification with the primer of BamHIW with Taq polymerase. (C) Amplification with the primer of BamHIW with LA Taq polymerase (TaKaRa)

In these experiments, we observed many alveolar macrophages in or around the lymphoproliferative regions. These macrophages expressed EBV by both the method of in situ hybridization and immunofluorescence. To confirm the macrophages, double staining for the macrophage marker, CD68, and BamHIW in situ hybridization, were performed. Large macrophages in or around the lymphoma or lymphoproliferative region were double stained (Fig. 4). Furthermore, indirect immunofluorescence staining with anti-BZLF1 revealed fluorescence in much larger cells, suspected to be macrophages. These results suggest that in the tissue of lymphoproliferative disorders, not only lymphoma cells and atypical lymphocytes, but also alveolar macrophages express EBV and that these macrophages express proteins associated with EBV proliferation as well as transformation.

\section{Discussion}

In this study, we showed that EBV infected all the lymphoproliferative disorders, and that the EBV-infected cells of these disorders were not only lymphocytes but also macrophages.

In the literature, the respiratory tract has been proved to be major reservoir for EBV (22). There are some reports of EBV detection in LIP (23-26) and in MALT lymphoma (27), whereas negative results have also been reported (28). In the DNA in situ hybridization using the BamHIW probe, 9 out of the 14 cases of LIP were described to be EBV-positive (23). By PCR amplification using the IR 3 region of EBV, 3 of the 6 cases of LIP were reported to be EBV-positive (24). LMP1 was described to be detected in a case of LIP (25) and in 10 of 13 cases of LIP in another study (26). Tao and Kahn reported a case of MALT lymphoma, which progressed from low-grade to high-grade, showing monoclonality of EBV by Southern blot hybridization and PCR (27). In this case, EBV was detected at first examination and the fact coincided with our results. On the contrary, Tamura et al reported that all 12

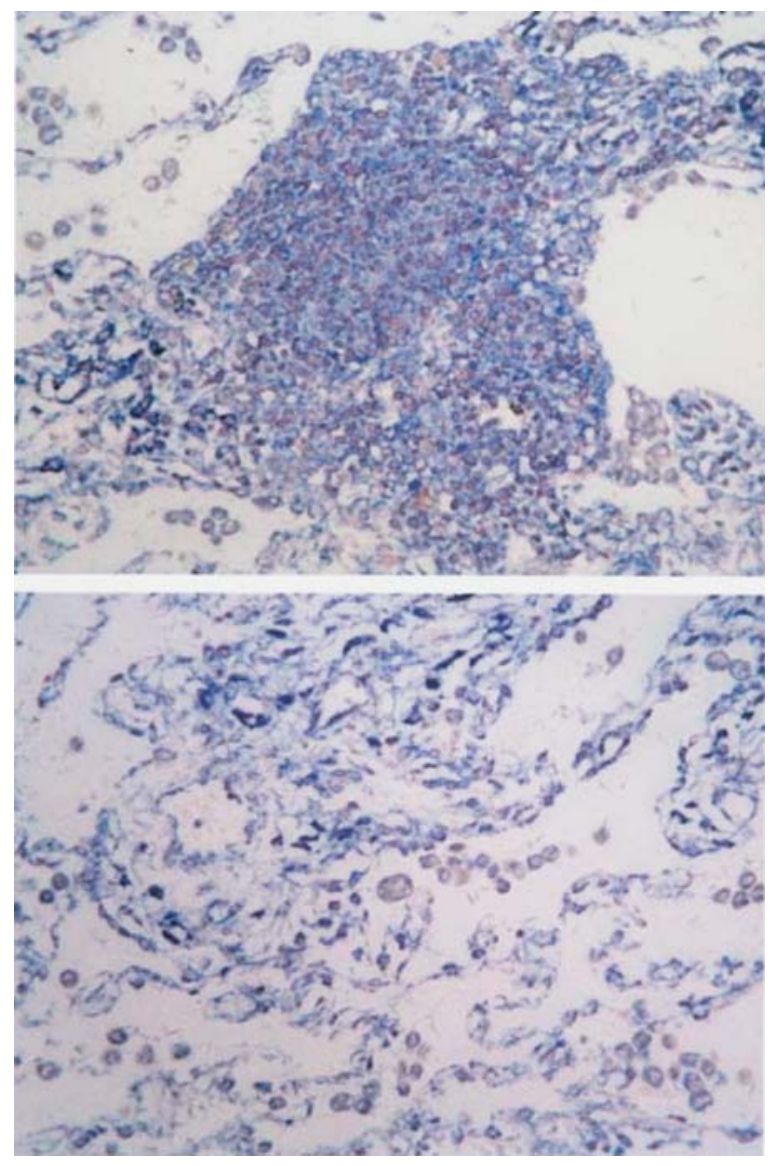

Figure 4. Double staining with BamHIW mRNA in situ hybridization and CD68. Large macrophages in (upper figure) and around (lower figure) the lymphoma and lymphoproliferative region were double stained. EBV mRNA was stained in purple-blue and CD68 was stained in brown. Upper, case 1; lower, case 4.

cases of MALT lymphoma showed no signal of EBER1 using in situ hybridization (28). Our experiments of EBER1 in situ hybridization also showed weak signals. Therefore, this discrepancy could depend on the method used for EBV detection. One possible reason could be the different sensitivity of the used probes. Our BamHIW probes did not contain an 'Alu-family'-like sequence, and so the reaction was considered to be specific to EBV. The antisense probe did not react with the EBV-negative cells. As the BamHIW fragment of EBV contains a 10-fold redundant sequence (19), this probe is very sensitive in detecting EBV. Furthermore, the BamHIW fragment is a leader sequence of the mRNAs of EBNAs (29), which are suspected to be oncogenes of EBV. Therefore, the BamHIW probe is important for the detection of EBV transformation. Moreover, we confirmed the expression of the oncogenic proteins, EBNA2 and LMP1, in this study. Our results with in situ hybridization and immunofluorescence suggest an oncogenic and tumor progressive role of EBV in lymphoproliferative disorders of the lung.

Hybridization signals and fluorescence were observed in all these experiments of lymphoproliferative diseases in the lung specimens. This fact showed that EBV infected cells of these disorders at early stages and that EBV infection did not occur accidentally in the long-term course of progression. 
We have shown EBV expression in macrophages (30) and Langerhans' cells (12,31). EBV expressed not only the transforming genes but also the replication protein in the macrophages (30). Also in this study, we confirmed the EBV expression in alveolar macrophages. The co-culture of several B-cell lymphoma lines with human macrophages revealed an enhancement of soft agar colony formation and growth in low serum concentration in a cell line of Namalwa, which was derived from Burkitt's lymphoma, but not in other cell lines (our results, data not shown). We suspect that macrophages have some roles in the transformation or progression of EBVassociated lymphoproliferative disorders of the lung. More study is necessary to clarify the function of macrophages. Inflammation and cancer has been discussed for many years $(32,33)$. MALT lymphomas are thought to originate from cells that are generated in response to various types of chronic inflammation (34). EBV-transformed lymphocytes and macrophages must be studied in this viewpoint.

\section{Acknowledgements}

We thank Dr M. Yutsudo (Osaka University) and Dr T. Akaike ( Kumamoto University) for their help during this study. We also thank Dr Harashima for his generous gift of B-cell lymphoma cell lines. This study was supported by a Grant-in-Aid for Cancer Research, from the Ministry of Health, Labour and Welfare of Japan.

\section{References}

1. Swigris JJ, Berry GJ, Raffin TA and Kuschner WG: Lymphoid interstitial pneumonia: A narrative review. Chest 122: 2150-2164, 2002.

2. Rickinson $A B$ and Kieff E: Epstein-Barr virus. In: Fields Virology. Fields BN, Knipe DM, Howley PM, et al (eds). 3rd edition. Lippincott-Raven Publishers, Philadelphia, pp2397-2446, 1996.

3. Shimakage M, Dezawa T, Tamura S, et al: A Ki-1-positive cell line expressing Epstein-Barr virus antigens established from a child with Ki-1-positive lymphoma. Intervirology 36: 215-224, 1993.

4. Shimakage M, Oka T, Shinka T, Kurata A, Sasagawa T and Yutsudo M: Involvement of Epstein-Barr virus expression in testicular tumors. J Urol 156: 253-257, 1996.

5. Shimakage M, Nakamine H, Tamura S, Takenaka T, Yutsudo M and Hakura A: Detection of Epstein-Barr virus transcripts in Anaplastic large-cell lymphomas by mRNA in situ hybridization. Hum Pathol 28: 1415-1419, 1997.

6. Shimakage M, Sasagawa T, Yoshino K, et al: Expression of Epstein-Barr virus in mesopharyngeal and hypopharyngeal carcinomas. Hum Pathol 30: 1071-1076, 1999.

7. Sasagawa T, Shimakage M, Nakamura M, Sakaike J, Ishikawa H and Inoue M: Epstein-Barr virus (EBV) genes expression in cervical intraepithelial neoplasia and invasive cervical cancer: A comparative study with human papillomavirus (HPV) infection. Hum Pathol 31: 318-326, 2000.

8. Shimakage $M$ and Sasagawa T: Detection of Epstein-Barr virusdetermined nuclear antigen- 2 mRNA by in situ hybridization. J Virol Methods 93: 23-32, 2001.

9. Shimakage M, Sasagawa T, Kawahara K, Yutsudo M, Kusuoka H and Kozuka T: Expression of Epstein-Barr virus in cutaneous Tcell lymphoma including mycosis fungoides. Int J Cancer 92: 226-231, 2001.

10. Shimakage M, Horii K, Tempaku A, Kakudo K, Shirasaka T and Sasagawa T: Association of Epstein-Barr virus with oral cancers. Hum Pathol 33: 608-614, 2002.
11. Shimakage M, Kawahara K, Sasagawa T, et al: Expression of Epstein-Barr virus in thyroid carcinoma correlates with tumor progression. Hum Pathol 34: 1170-1177, 2003.

12. Shimakage M, Sasagawa T, Kimura M, et al: Expression of Epstein-Barr virus in Langerhans' cell histiocytosis. Hum Pathol 35: 862-868, 2004.

13. Hammerschmid W and Sugden B: Genetic analysis of immortalizing functions of Epstein-Barr virus in human B lymphocytes. Nature 340: 393-397, 1989.

14. Shimakage M, Kurata A, Inoue H, Okamoto Y,Yutsudo M and Hakura A: Tumorigenicity of EBNA2-transfected cells. FEBS Lett 371: 245-248, 1995.

15. Wang D, Liebowitz D and Kieff E: An EBV membrane protein expressed in immortalized lymphocytes transforms established rodent cells. Cell 43: 831-840, 1985.

16. Rosa MD, Gottlieb E, Lerner MR and Steitz JA: Striking similarities are exhibited by two small Epstein-Barr virus-coded ribonucleoc acids and adenovirus-associated ribonucleic acids VAI and VAII. Mol Cell Biol 1: 785-796, 1981.

17. Miller G: The switch between latency and replication of Epstein-Barr virus. J Infect Dis 161: 833-844, 1990.

18. Shimakage M, Harada S, Kawahara K, et al: Detection of Epstein-Barr virus nuclear antigen leader protein expression in various human cancers. In: New Developments in Epstein-Barr Virus Research. Umar CS (ed). Nova Science Publishers, Inc., New York, pp261-276, 2006.

19. Cheung A and Kieff E: Long internal direct repeat in EpsteinBarr virus DNA. J Virol 44: 286-294, 1982.

20. Tierney RJ, Steven N, Young LS and Rickinson AB: EpsteinBarr virus latency in blood mononuclear cells, analysis of viral gene transcription during primary infection and in the carrier state. J Virol 68: 7374-7485, 1994.

21. Finke J, Rowe M, Kallin B, et al: Monoclonal and polyclonal antibodies against Epstein-Barr virus nuclear antigen 5 (EBNA5) detect multuple protein species in Burkitt's lymphoma and lymphoblastoid cell lines. J Virol 61: 3870-3878, 1987.

22. Lung ML, Lam WK, So SY, Lam WP, Chan KH and Ng MH: Evidence that respiratory tract is major reservoir for EpsteinBarr virus. Lancet 1: 889-892, 1985.

23. Barbera JA, Hayashi S, Hegele RG and Hogg JC: Detection of Epstein-Barr virus in lymphocytic interstitial pneumonia by in situ hybridization. Am Rev Respir Dis 145: 940-946, 1992.

24. Malamou-Mitsi V, Tsai MM, Gal AM, Koss MN and O'Leary TJ: Lymphoid interstitial pneumonia not associated with HIV infection: Role of Epstein-Barr virus. Mod Pathol 5: 487-491, 1992.

25. Klein C, Rosenberger S, Niemeyer C, et al: EBV-associated lymphoproliferative syndrome with a distinct 69 base-pair deletion in LMP-1 oncogene. Br J Hematol 91: 938-940, 1995.

26. Kaan PM, Hegele RG, Hayashi S and Hogg JC: Expression of bcl-2 and Epstein-Barr virus LMP1 in lymphocytic interstitial pneumonia. Thorax 52: 12-16, 1997.

27. Tao J and Kahn L: Epstein-Barr virus-associated high-grade Bcell lymphoma of mucosal-associated lymphoid tissue in a 9year-old boy. Arch Pathol Lab Med 124: 1520-1524, 2000.

28. Tamura A, Kitagawa M, Komatsu H, et al: Does an EpsteinBarr viral infection influence the pathogenesis of a primary pulmonary B-cell lymphoma? Lung 173: 385-387, 1995.

29. Bodescot $\mathrm{M}$ and Perricaudet $\mathrm{M}$ : Clustered alternative splicing sites in Epstein-Barr virus RNAs. Nucleic Acids Res 15: 5887, 1987.

30. Shimakage M, Kimura M, Yanoma S, et al: Expression of latent and replicative-infection genes of Epstein-Barr virus in macrophage. Arch Virol 144: 157-166, 1999.

31. Shimakage M: Association of EBV in Langerhans cell histiocytosis - reply. Hum Pathol 37: 1509-1511, 2006.

32. Balkwill $\mathrm{F}$ and Manntovani A: Inflammation and cancer: back to Virchow? Lancet 357: 539-545, 2001.

33. Coussens LM and Werb Z: Inflammation and cancer. Nature 420: 860-866, 2002

34. Seto M: Genetic and epigenetic factors involved in B-cell lymphomagenesis. Cancer Sci 95: 704-710, 2004. 